\title{
Pattern of Early Neonatal Morbidities in Moderate and Late Pre-terms
}

\author{
Kumari K' ${ }^{1}$ Rao K.A $\mathbf{2}^{2}$, Vijayalakshmi B ${ }^{3}$ \\ ${ }^{1}$ Dr. KantaKumari, Assistant Professor, ${ }^{2}$ Dr. K. Anantha Rao, Assistant Professor, ${ }^{3}$ Dr. Bhimireddy Vijayalakshmi, HOD \\ \& Professor, all authors are attached with Department of Paediatrics, NRI General Hospital, Guntur, Andhra Pradesh, \\ India.
}

Address for correspondence: Dr. KantaKumari, Email: kantakumari@hotmail.com

\begin{abstract}
Objective: The present study is an attempt to analyze the data on the pattern of early neonatal morbidities among moderate and late preterm infants of 32 full weeks of gestation to $36^{+6}$ weeks' gestational age in a tertiary care teaching hospital with a level III NICU, Chinna Kakani, A.P. Materials and Methods: The study was a retrospective analysis of all live born preterms of $32^{+0}-36^{+6}$ GA, who were admitted between January, 2015 to April, 2016, over a period of 16 months. Data collected from hospital medical records of neonates were reviewed and analyzed statistically. Results: Of total of 3067 deliveries conducted, 930 babies were admitted in NICU for various reasons. Of total admissions to NICU $125(13 \%)$ infants were termed as moderate and late preterms after checking their GA and analyzed for the spectrum of early neonatal morbidities during their stay in hospital. Of total 125 babies, $58 \%(n=68)$ were moderate preterms and $45 \%$ $(n=57)$ were late preterms, 75\% $(n=94)$ of them were AGA and 25\% $(n=32)$ were SGA. Of them, 62\% ( $n=77)$ were delivered by LSCS while $38 \%(n=48)$ were delivered by NVD. Male infants comprised of $54 \%(n=67)$ while females were $46 \%(n=58)$. The mean weight at birth was $1.86 \mathrm{~kg}$. Around $62 \%(\mathrm{n}=78)$ of babies were observed for $\mathrm{RD}$, of which $28 \%(n=35)$ required CPAP and 23\%(n=29) for mechanical ventilation, $18 \%(n=23)$ had apneas. Most common metabolic abnormality was hyper bilirubinemia at 44\% $(\mathrm{n}=55)$ requiring phototherapy. Around $7 \%(\mathrm{~N}=9)$ received parenteral nutrition, NEC observed in 3\% ( $\mathrm{n}=3)$. Maternal co morbid conditions were associated in about $60 \%$ of cases. Conclusion: Moderate preterms were significantly at a higher risk for over all morbidities, longer duration of hospital stays and at a high risk for mortality when compared to late preterms. Moderate and late preterm infants place high demands on specialist neonatal services.
\end{abstract}

Keywords: Moderate Preterms, Morbidity, Respiratory Distress, CPAP

\section{Introduction}

Preterm labor is defined as live birth delivery before 37 complete weeks of gestation, and is the main determinant of neonatal morbidity and mortality around the world [1]. Gestational age can be classified as, if $<$ 28 weeks as extreme preterm, 28-32 weeks as very preterm and $32^{+0}-36^{+6}$ weeks, as moderate to late preterm.

Prematurity is the leading cause of death in the $1^{\text {st }}$ four weeks of life and $2^{\text {nd }}$ most common cause after pneumonias in $<5$ yrs. Preterm birth rate continues to raise around the world mainly at the expense of late preterm newborns. Around 15 million babies are born prematurely and one million children die secondary to

Manuscript received: $6^{\text {th }}$ June 2016

Reviewed: $13^{\text {th }}$ June 2016

Author Corrected; $27^{\text {th }}$ June 2016

Accepted for Publication: $11^{\text {th }}$ July 2016 complications related to premature births [2]. The vast majority of $(85 \%)$ global pre mature births occur in Asia and Africa where health systems are weak and access to and utilization of health services are limited, contributing to high risk of death and disabilities in preterm babies [3]. The incidence of premature birth has been increasing over recent decades across the world, and the rise is primarily the result of inclusion of a group of border line preterm infants since 2005. A new classification was created in order to focus on this group of border line infants who are still premature and as a result, should not receive care as FTI. Fetal growth and maturation occur along a continuum throughout pregnancy. For example, late preterm babies are born within the final stages of saccular stage of lung maturation (26-36 weeks of gestation). Premature birth during this critical respiratory maturation period may 
result in significant alteration in lung function and physiology, like wise brain maturation and the increase in brain weight are significantly higher during last trimester.

There has traditionally been lack of consensus on standard gestational age categories for infants born in the period near to term i.e. for 32- 37 weeks of gestation [4]. Lack of recognition of prematurity and its importance of physical and neuro cognitive sequelae, could lead to increased comfort with early elective deliveries, less rigorous NB assessment, early discharges or inadequate monitoring.

Preterm birth is not a single entity, but a common final outcome of a heterogeneous collection of under lying maternal and fetal factors. Around $1 / 3^{\text {rd }}$ of all preterm births are the result of medical interventions to protect the health of mother or infant. Concern over the practice of elective induction or caesarian deliveries without medical indication prompted the March of Dimes to launch national campaign, "healthy babies are worth wait", to raise awareness among patients and providers on the importance of preventing non-indicated intervention [5].

Late preterm births comprise of $50-90 \%$ of premature births and associate with smaller but statistically significant neonatal mortality risk. During the last decade, studies showed that late and moderate preterm were at a higher risk for neonatal complications, including respiratory distress, requiring ventilation, TTN, IVH, bacterial sepsis, apneas, hypoglycemia, hyper bilirubinemia, feeding difficulties, NICU admissions and deaths [4,6,7]. More than $60 \%$ of all preterm births in Asia and Africa occur after 32 weeks of gestation and deaths in almost all these babies can be prevented by essential new born care. In areas with appropriate facilities for deliveries and post delivery care, clinical interventions such as surfactant administration and CPAP might improve survival to a large extent. Evidence based, low cost interventions were feasible for LMICs (Low and Middle income countries) and could reduce mortality related to preterm birth complications, such as antenatal steroids, KMC, and treatment of neonatal infections $[2,5,8]$.

\section{Methods and Materials}

This is a retrospective, hospital based study, carried out byenrolling all live born preterm babies between $32^{+0}$ $36^{+6}$ weeks' gestational age, born in NRIGH maternity unit. It's a tertiary care teaching hospital with level-III NICU facilities catering patients from lower to upper middle class strata.

Study period: Jan 2015 - April 2016 (16 months). Study was approved by institutional ethical committee. Data collected from medical records of the preterm babies who were admitted during the study period were reviewed. Data regarding gestational age, birth weight, causes of preterm birth, duration of hospital stay, various morbidity and mortality patterns and treatment provided in the NICU were reviewed. A suitable case reporting form (CRF) was developed for the study after reviewing the files for infant particulars, risk factors, and morbidities. Gestational age was assessed by mother's last menstrual period, 1st trimester ultrasonogram, and new Ballard scoring.

Inclusion criteria: All live born babies between $32^{+0}-$ $36^{+6}$ weeks' gestation.

Exclusion criteria: Out born, still born, and major identifiable chromosomal anomalies.

The objective was to assess the profile and magnitude of early morbidities among the moderate and late preterms admitted in our NICU. The relative frequency of individual variables were calculated.

\section{Results}

During the study period of sixteen months, a total of 3067 deliveries were conducted in the maternity unit of NRIGH, of which 930 babies (30\% of all deliveries) were admitted to NICU due to various reasons, out of these 125 babies (13\%) were selected after checking their gestational ages between 32/o -36/6 weeks and termed as moderate and late preterm babies. These infants were analyzed for pattern of early morbidities during their hospital stay till their discharge. Of total 125 babies, $58 \%(n=68)$ were moderate preterm and $45 \%(n=57)$ were late preterm, 75\% $(n=94)$ of the total were AGA (appropriate for gestational age), and 25\% $(\mathrm{n}=32)$ were SGA (small for gestational age).

1. Mode of delivery: $62 \%(n=77)$ of them were delivered by LSCS while $38 \%(n=48)$ were delivered by NVD (Normal Vaginal Delivery). 
Table- 1: Base line variables of study population.

\begin{tabular}{|c|c|c|c|c|c|c|c|}
\hline Variable & GA32-36 $^{+6}$ & $\begin{array}{c}\begin{array}{c}\text { \%of } \\
n=125\end{array} \\
\end{array}$ & GA $32-33^{+6}$ & $\begin{array}{l}\% \text { of } \\
n=68\end{array}$ & $\begin{array}{c}\text { GA 34- } \\
3^{+6}\end{array}$ & $\begin{array}{l}\% \text { of } \\
n=57\end{array}$ & $\begin{array}{l}Z \text { value/P- } \\
\text { Value }\end{array}$ \\
\hline Mean Birth wt. (kg) & 1.8 & - & 1.65 & - & 2.06 & - & \\
\hline Male & 67 & 53 & 38 & 56 & 29 & 51 & \\
\hline Female & 58 & 46 & 30 & 44 & 28 & 49 & \\
\hline Wt. of $\mathrm{NB}>2.5 \mathrm{Kg}$ & 5 & 4 & 0 & 0 & 5 & 9 & \\
\hline $\begin{array}{c}\text { Wt. of NB } 1.5-2.49 \\
\text { Kg }\end{array}$ & 86 & 69 & 39 & 57 & 47 & 82 & $2.99 / 0.002$ \\
\hline Wt. of $\mathrm{NB}<1.5 \mathrm{Kg}$ & 34 & 27 & 29 & 43 & 5 & 9 & $4.24 / 0.0001$ \\
\hline NVD & 48 & 38 & 29 & 43 & 19 & 33 & \\
\hline LSCS & 77 & 61 & 39 & 57 & 38 & 67 & \\
\hline AGA & 94 & 75 & 55 & 81 & 39 & 68 & $1.67 / 0.09$ \\
\hline SGA & 31 & 25 & 13 & 19 & 18 & 32 & \\
\hline
\end{tabular}

Table- 2: Respiratory Morbidity Pattern in moderate and late pre-terms.

\begin{tabular}{|c|c|c|c|c|c|c|c|}
\hline $\begin{array}{c}\text { Respiratory } \\
\text { Morbidity }\end{array}$ & GA $32^{+0}-36^{+6}$ & $\begin{array}{c}\text { \%of } n= \\
125\end{array}$ & $\begin{array}{c}\text { GA 32- } \\
3^{+6}\end{array}$ & $\begin{array}{l}\% \text { of } \\
n=68\end{array}$ & $\begin{array}{c}\text { GA 34- } \\
36^{+6}\end{array}$ & $\begin{array}{l}\% \text { of } \\
n=57\end{array}$ & $\begin{array}{c}\text { z-value/p- } \\
\text { value }\end{array}$ \\
\hline $\mathrm{RD}$ & 78 & 62 & 50 & 74 & 28 & 49 & $2.87 / 0.004$ \\
\hline Surfactant & 5 & 4 & 4 & 6 & 1 & 2 & $1.11 / 0.26$ \\
\hline Antenatal Steroids & 31 & 25 & 23 & 34 & 8 & 14 & $2.57 / 0.01$ \\
\hline CPAP & 35 & 28 & 25 & 37 & 10 & 18 & $2.34 / 0.01$ \\
\hline $\begin{array}{l}\text { Mechanical } \\
\text { Ventilator }\end{array}$ & 29 & 23 & 17 & 25 & 12 & 21 & $0.52 / 0.59$ \\
\hline Apneas & 23 & 18 & 17 & 25 & 6 & 11 & $2.002 / 0.04$ \\
\hline
\end{tabular}

Table 3: Other Morbidities.

\begin{tabular}{|c|c|c|c|c|c|c|c|}
\hline Variable & $\begin{array}{c}\text { GA 32 } 2^{+0} \\
36^{+6}\end{array}$ & $\begin{array}{c}\% \text { off } \\
n=125\end{array}$ & GA $32-33^{+6}$ & $\%$ of $n=68$ & $\begin{array}{c}\text { GA 34- } \\
3^{+6}\end{array}$ & $\begin{array}{l}\% \text { of } \\
\text { n=57 }\end{array}$ & Z \& P Value \\
\hline $\begin{array}{l}\text { Jaundice with } \\
\text { Photo Therapy }\end{array}$ & 55 & 44 & 33 & 50 & 22 & 39 & $1.23 / 0.21$ \\
\hline $\begin{array}{l}\text { Parenteral } \\
\text { Nutrition }\end{array}$ & 9 & 7 & 8 & 12 & 1 & 2 & $2.12 / 0.03$ \\
\hline Clinical Sepsis & 62 & 50 & 36 & 53 & 26 & 45 & $0.89 / 0.37$ \\
\hline Proven Sepsis & 7 & 5.6 & 4 & 6 & 3 & 5 & $0.24 / 0.80$ \\
\hline Shock & 47 & 37 & 29 & 42 & 18 & 31 & $1.26 / 0.20$ \\
\hline Neurological & 19 & 15 & 13 & 20 & 6 & 10 & $1.54 / 0.12$ \\
\hline $\mathrm{NEC}$ & 3 & 2.5 & 2 & 3 & 1 & 2 & $0.35 / 0.72$ \\
\hline Cardiovascular & 9 & 7 & 7 & 10 & 2 & 5 & $1.04 / 0.29$ \\
\hline
\end{tabular}

Table 4: Outcome of Admitted Neonates in NICU.

\begin{tabular}{|c|c|c|c|c|c|}
\hline Variable & GA $32^{+0}-33^{+6}$ & \%of $n=68$ & GA 34-36 ${ }^{+6}$ & \%of $n=57$ & P-Value \\
\hline Death & 3 & 2.5 & 0 & 0 & \\
\hline Hospital Stay & 14days & & 6.5 days & & \\
\hline
\end{tabular}

2. Sex distribution: About $54 \%(n=67)$ were male and $46 \%(n=58)$ were female babies, with a ratio of $M: F=1: 1.6$. The mean weight at birth was $1.86 \mathrm{Kgs}$. 
3. Respiratory morbidities:Around $25 \%(\mathrm{n}=31)$ received antenatal steroids. $62 \%(\mathrm{n}=78)$ of them developed respiratory distress early in life either in the form of TTN, RDS, or MAS. Of those who had RD, $28 \%(\mathrm{n}=35)$ required CPAP \& $23 \%$ $(\mathrm{n}=29)$ required mechanical ventilator support either soon after birth or after failed CPAP support. Only $4 \%(\mathrm{n}=5)$ received surfactant. $18 \%(\mathrm{n}=23)$ developed recurring apneas requiring caffeine or aminophylline treatment. Other respiratory morbidities identified were congenital pneumonias, pulmonary hemorrhages, and air leak syndromes at $4 \%$ $(\mathrm{n}=5)$ each of them.

4. Metabolic morbidities: Most common was hyper bilirubinemia at $44 \%(n=55)$ requiring photo therapy. Apart from hyper bilirubinemia, other metabolic abnormalities including hypo glycaemia, hypocalcemia, metabolic or respiratory acidosis, etc. were identified in $19 \%(n=24)$ of the babies. Around $51 \%(n=62)$ had clinical sepsis, while positive cultures grown were found in $5.6 \%(\mathrm{n}=7)$ cases only. $27 \%(\mathrm{n}=34)$ had circulatory insufficiency or shock, and about $10 \%(\mathrm{n}=13)$ developed DIC during their stay. Around 38\% $(\mathrm{n}=48)$ of babies received blood products in the form of PRBCs, FFP, or platelets for various reasons like anemia, shock, DIC or thrombocytopenia. One baby received intravenous Ig (immunoglobulins) and three babies required DVET (double volume exchange transfusion) for Rh incompatibility.

5. Cardiac morbidities: 2D Echo was done on most of the babies during their stay in NICU. Around $22 \%(\mathrm{n}=8)$ of them had trivial lesions in the form of small PDA, small ASD, or PFO which required no interventions. Around $6 \%(\mathrm{n}=8)$ of the babies' required medical management in the form of Sildenafil, Ibuprofen or Lasix for conditions like PPHN, PDA, or CCF, while one case required surgical ligation for PDA.

6. Neurological Morbidities: I.V.H (Intra Ventricular Hemorrhage) was found in $4 \%(\mathrm{n}=5)$ of cases, HIE grade II - III (hypoxic ischemic encephalopathy) found in $3 \%,(\mathrm{n}=4)$ and seizures in $8 \%$ of the babies.

7. Feeding difficulties: Depending upon the neonate's clinical condition, most of the babies were started on venous infusions initially until they are fit for either direct breast feeds or EBM through OG feeds. As our institute is baby friendly and we advocate exclusive breast feeds, very rarely supplementary feeds were given. Around $7 \%(n=9)$ of the babies received parenteral nutrition. Among the admitted babies NEC was identified in $2.5 \%(\mathrm{n}=3)$ of the babies. Though not major, about $7 \%(\mathrm{n}=15)$ of them had congenital malformations in the form of absent kidney, polydactyly, hypospadias, cleft lip, cleft palate, etc.

8. Maternal co-morbid conditions: No or minimal risk factors were found in $33 \%(\mathrm{n}=42)$ of cases. Around $60 \%$ of them had one or more pregnancy related or maternal medical conditions which might contribute to neonatal morbidity. HTN (hyper tension) syndromes including preexisting HTN, PIH (pregnancy induced HTN), Eclampsia were observed in 20\% $(\mathrm{n}=24)$, DM syndromes (diabetes mellitus) including GDM (gestational DM), DM type 1, DM type 2 comprised of 10\% $(\mathrm{n}=13), \operatorname{PPROM}$ ( pre term premature rupture of membranes) were seen in $12 \%(\mathrm{n}=15)$, Oligohydramnios in about $20 \%$ $(\mathrm{n}=26)$, Multiple pregnancies including Twins in about $13 \%(\mathrm{n}=14)$, Maternal infectionssuch as HIV, Hep-B, UTI, Bacterial vaginosis, maternal fevers prior to labor etc. constituted about 13\% $(\mathrm{n}=6)$. BOH (Bad Obstetric History) in 6\%, others like APH (including placenta previae, abruptio placentae), Breech, Fetal distress, Rh incompatibility comprised of $3 \%$ each. Several miscellaneous conditions observed were HELLP Syndrome, PCOD, Fibroids, Seizures, Polyhydramnios, Anemia, Connective tissue disorders etc.

TABLE 2, 3, 4, On comparing moderate to late preterms, significant differences were found in certain morbidities and were at significantly high risk for overall morbidity due to any cause.

Respiratory complications were ranking high, in the form of respiratory distress, requiring ventilatory support, apneas of prematurity, number of mothers who had received prenatal steroids were much higher in moderate preterms compared to late preterms. Similarly, they were also at a higher risk for metabolic and infectious complications such as, around $50 \%$ needed photo therapy for jaundice, $12 \%$ of them needed parenteral nutrition until feeds were tolerated, about $50 \%$ of them had clinical sepsis requiring empiric antibiotics, and around $30 \%$ of them went into shock during their stay requiring ionotropes. Regarding neurological morbidities at least $20 \%$ of moderate preterms had complications such as I.V.H (intra ventricular hemorrhage), H.I.E (hypoxic ischemic encephalopathy) gr II-III and seizures while in late preterms it is about $10 \%$. 
Mean duration of stay for moderate preterms was 14 days while for late preterms it was 6.5 days. Amongst the 32-34 weeks GA, the observed mortality due to various reasons was $2.5 \%(\mathrm{n}=3)$, while no mortalitywas observed in $34-36$ weeks GA. during their stay in NICU.

\section{Discussion}

Late and moderate preterm infants are both physiologically and developmentally immature and have higher risks for morbidity and mortality compared with infants born at term. The major findings of our study were that the risk for any short-term morbidity in moderate and late preterm infants is clearly related to gestational age.

The most commonly observed morbidities were hyperbilirubinemia, respiratory problems and need for parenteral nutrition. Previous studies compared late preterm infants outcome with term infants $[4,9,1]$. However, the differences between those born at 32-36 weeks suggest that it is inappropriate to regard moderate and late-preterm infants as a homogeneous group with respect to neonatal morbidity and mortality [11].

Our study shows that the rate of admissions for $32+0-$ $36+6$ weeks gestation was $40 / 1000$ live births with an incidence of $4 \%$. Of which $2.2 \%$ were moderate preterms and $1.8 \%$ were late preterms.

There was a higher rate of LSCS in this study population probably because of high risk expectant mothers being referred to our tertiary care maternity unit. There were more male infants observed; however, this was similar to previous studies [12].

Gestational age and maternal co-morbidities were risk factors for adverse neonatal outcome [13]. Around 60\% of the study group had associated maternal comorbidities that led to either spontaneous or induced labour culminating into preterm labour.

In our study around $60 \%$ of infants (especially moderate preterms) experienced respiratory compromises requiring ventilation, CPAP, apneas, similar to study by Kirby [14], which demonstrates the immaturity of their respiratory systems. The incidence of respiratory complications was higher in the $32-34$ weeks GA group compared to the 34-36 weeks of GA group (table 2).

A significant number (44\%) had hyperbilirubinemia requiring photo therapy. The level of hyperbilirubinemia was higher and needed longer duration of phototherapy in the moderate preterm infants group compared to late preterm infantsgroup. These findings weresimilar to the observations found in revious studies[10, 15, 16]. A quarter of the study group were classified as SGA, which might be secondary to poor maternal health status, poor socio economic status or associated co morbidities like pregnancy induced HTN, eclampsia etc.

According to UNICEF 'the state of worlds children 2010 ' report $28 \%$ of the neonates are born with low birth weight in India. Pulver et al. [17] reported that the risk of death during 1st month of life was 40 times greater among late preterms classified as SGA than among the late preterms with AGA.

The estimated prevalence of SGA is highest in South Asia and Africa. India has the world's largest number of SGA births, 12.8 million in 2010, due to the large number of births and the high proportion, $46.9 \%$, of births that are SGA [18].

In addition to feeding problems secondary to immaturity of GIT, impaired sucking and deglutition mechanisms are often barriers to establish successful breast feeding leading to excessive weight loss, and longer stay in NICU. About $7 \%$ of the study group received parenteral nutrition, except for one baby from late preterm, all of them belong to moderate preterms.

Hypoglycemia was a rare event in our study, except for a few instances in infants of diabetic mother's, as most of them were either on venous infusions or breast feeds depending on their clinical condition.

About $50 \%$ of the admitted babies were treated for clinical sepsis, though culture proven sepsis was about $5 \%$. Several studies show variable incidence like Wang et al. [4] 36\%, Jaiswal et al. [16] 4\% and Melamed et al. [10] 19\%. Our study also shows significant difference between moderate and late preterm morbidities, in spite of receiving antenatal steroids and surfactant, their requirement for respiratory support, incidence of neonatal jaundice, sepsis, neurological morbidities, feeding difficulties were high, requiring close monitoring compared to late preterm infants [19]. 


\section{Conclusion}

The high rate of neonatal morbidity in our study may be attributed to the inclusion of moderate preterms who had outnumbered the late preterms. Moderate preterms had shown to have more difficult transition to extra uterine life and required to stay longer in NICU and need extra attention and special care to prevent adverse events.

The guidelines for these babies need to be reviewed, looking for possible causes as well as developing evidence based protocols for close monitoring to minimize the morbidity and to bring awareness among obstetricians about the risks of premature birth related morbidities.

Limitations: Major limitation is its retrospective design, relatively small sample size, single center study. Since its a tertiary care referral center, number of high risk mothers were referred with antenatal complications.

Majority of our study group comprised of moderate preterms. Hence high incidence of morbidities may be observable and most of the patients had a low socioeconomic status, the results of this study may not reflect the actual burden which is prevalent in the community as a whole.

\footnotetext{
Abbreviations

AGA - Appropriate Gestational Age, APH - Ante Partum Hemorrhage, ASD - Atrial Septal Defect, BOH -Bad Obstetric History, CCF - Congestive Cardiac Failure, CPAP - Continuous Positive Airway Pressure, DIC - Diffuse Intra Vascular Coagulation, DVET Double Volume Exchange Transfusion, EBM Expressed Breast Milk, FFP - Fresh Frozen Plasma FTI - Full Term Infant, GA - Gestational Age, GIT - Gastro Intestinal Tract, HIE - Hypoxic Ischemic Encephalopathy, HTN - Hyper Tension, IVH - Intra Ventricular Hemorrhage, KMC - Kangaroo Mother Care, LSCS - Lower Segment Caesarian Section, MAS

- Meconium Aspiration Syndrome, MV - Mechanical Ventilation, NEC -Necrotising Enterocolitis, NICU Neonatal Intensive Care, NVD - Normal Vaginal Delivery, OG Feeds - Orogastric Feeds, PCOD - Poly Cystic Ovarian Disease, PDA - Patent Ductus Arteriosus, PFO - Patent Foramen Ovale, PIH Pregnancy Induced Hypertension, PPHN - Persistent Pulmonary Hyper Tension, PRBC - Packed Red Blood Cells, RDS - Respiratory Distress Syndrome, SGA Small Gestational Age, TTN - Transient Tachypnea of
}

New Born, UTI - Urinary Tract Infection.

Funding: Nil, Conflict of interest: Nil Permission from IRB: Yes

\section{References}

1. Goldenberg RL, Culhane JF, Iams JD, Romero R. Epidemiology and causes of preterm birth.Lancet. 2008Jan 5;371(9606):75-84. doi: 10.1016/S0140-6736 (08)60074-4. Review. PMID: 18177778

2.Howson CP, Kinney MV, McDougall L, Lawn JE; Born Too Soon Preterm Birth Action Group.Reprod Health. 2013;10 Suppl 1:S1. doi: 10.1186/1742-475510-S1-S1. Epub 2013 Nov 15. Review. PMID: 24625113

3. Lawn JE, Gravett MG, Nunes TM, Rubens CE, Stanton C; GAPPS Review Group. Global report on preterm birth and stillbirth (1 of 7): definitions, descriptionof the burden and opportunities to improve data. BMC Pregnancy Childbirth. 2010 Feb 23;10 Suppl 1:S1. doi: 10.1186/1471-2393-10-S1-S1.PMID: 20233382

4. Wang ML, Dorer DJ, Fleming MP, Catlin EA. Clinical outcomes of near-term infants. Pediatrics. 2004 Aug;114(2):372-6. PMID: 15286219.

5. Howson CP, Kinney MV, McDougall L, Lawn JE; BornTooSoon Preterm Birth Action Group.Reprod Health. 2013;10 Suppl 1:S1. doi: 10.1186/1742-475510-S1-S1. Epub 2013 Nov 15. Review. PMID: 24625113

6. Escobar GJ, Clark RH, Greene JD. Short-Term Outcomes of Infants Born at 35 and 36 Weeks Gestation: We Need to Ask More Questions. Semin Perinatol. 2006 Feb; 30(1):28-33. Review. PMID: 16549211.

7. Hibbard JU, Wilkins I, Sun L, Gregory K, Haberman S, Hoffman M, et al. Respiratory Morbidity in Late Preterm Births. JAMA. 2010 Jul 28;304(4):419-25. doi: 10.1001/jama.2010.1015.PMID: 20664042.

8. Lawn JE, Mwansa-Kambafwile J, Horta BL, Barros FC, Cousens S. "Kangaroo mother care" to prevent neonatal deaths due to preterm birth complications. Int $\mathrm{J}$ Epidemiol. 2011 Apr;40(2):525-8. PMID: 21062786. 
9. Khashu M, Narayanan M, Bhargava S, Osiovich H. Perinatal outcomes associated with preterm birth at 33 to 36 weeks' gestation: apopulation-based cohort study. Pediatrics. 2009 Jan;123(1):109-13. doi: 10.1542/peds. 2007-3743. PMID: 19117868

10.Melamed N, Klinger G, Tenenbaum-Gavish K, Herscovici T, Linder N, Hod M, et al. Short-term neonatal outcome in low-risk, spontaneous, singleton, late preterm deliveries. Obstet Gynecol. 2009 Aug;114 (2 Pt 1):253-60. doi: 10.1097/AOG.0b013e3181af6931. PMID: 19622985

11. Young PC, Glasgow TS, Li X, Guest-Warnick G, Stoddard G. Mortality of late-preterm (near-term) newborns in Utah. Pediatrics. 2007 Mar;119(3):e65965.PMID: 17332185

12. Raju TNK, Higgins RD, Stark AR, Leveno KJ. Optimizing care and outcome for late-preterm (nearterm) infants: a summary of the workshop sponsored by the National Institute of Child Health and Human Development. Pediatrics. 2006 Sep;118(3):120714.PMID: 16951017

13. Shapiro-Mendoza CK, Tomashek KM, Kotelchuck M, Barfield W, Weiss J, Evans S. Risk factors for neonatal morbidity and mortality among "healthy," late preterm newborns. Semin Perinatol. 2006 Apr;30(2):5460.PMID: 16731277

14. Kirkby S, Greenspan JS, Kornhauser M, Schneiderman R. Clinical outcomes and cost of the moderately preterm infant. Adv Neonatal Care. 2007
Apr;7(2):80-7.PMID: 17605448.

15. Medoff Cooper B, Holditch-Davis D, Terese Verklan M, Fraser-Askin D, Lamp J, Santa-Donato A, Onokpise B, Soeken KL, Bingham D.Newborn Clinical Outcomes of the AWHONN Late Preterm Infant ResearchBased Practice Project. J Obstet Gynecol Neonatal Nurs. 2012 Nov-Dec;41(6):774-85. doi: 10.1111/j.1552-6909.2012.01401.x. Epub 2012 Aug 3.PMID: 22861492.

16. Jaiswal A, Murki S, Gaddam P, Reddy A. Early neonatal morbidities in late preterm infants. IndianPediatr. 2011 Aug;48(8):607-11. Epub 2010 Nov 30.PMID: 21169647.

17. Pulver LS, Guest-Warnick G, Stoddard GJ, Byington CL, Young PC. Weight for gestational age affects the mortality of late preterm infants. Pediatrics. 2009 Jun;123(6):e1072-7. doi: 10.1542/peds.20083288. PMID: 19482740

18. Black RE. Global Prevalence of Small for Gestational Age Births. Nestle Nutr Inst Workshop Ser. 2015;81:1-7. doi: 10.1159/000365790. Epub 2015 Jun 16.PMID: 26111558

19. Kerstjens JM, Bocca-Tjeertes IF, de Winter AF, Reijneveld SA, Bos AF. Neonatal Morbidities and Developmental Delay in Moderately Preterm-Born Children. Pediatrics. 2012 Aug;130(2):e265-72.doi: 10.1542/peds.2012-0079. Epub 2012 Jul 9.PMID: 22778308

\section{How to cite this article?}

Kumari K, Rao K.A, Vijayalakshmi B. Pattern of Early Neonatal Morbidities in Moderate and Late Pre-terms. Int J PediatrRes.2016;3(7):516-522.doi:10.17511/ijpr.2016.i07.10. 